\title{
Oferta Pública Educacional e o Background Familiar: Evidências para as Microrregiões Brasileiras de 2000 e 2010
}

\section{Educational Public Supply and the Familiar Background: Evidence for Brazilian Micro-Regions 2000 and 2010}

\author{
Fernanda Leite Santana* \\ José Luis da Silva Netto Júnior**
}

Resumo: O estudo busca avaliar a oferta dos serviços públicos educacionais nos ensinos fundamental e médio das microrregiões brasileiras no período de 2000 e 2010, bem como averiguar suas relações com a mobilidade intergeracional educacional. Para tanto, emprega-se duas estratégias empíricas aplicadas aos dados do censo escolar e dos censos demográficos. Na primeira, por meio da análise envoltória de dados (DEA), estima-se o índice de cobertura educacional (ICE), baseado na abordagem de Puig-Junoy (1999). Os resultados sugerem que o nível de cobertura educacional, tanto do ensino médio quanto do fundamental, apresentou uma melhoria no período estudado. A segunda visa aplicar um modelo econométrico embasado em Ferreira e Veloso (2003), no qual sugerem que microrregiões com maior eficiência quanto à oferta pública de educação apresentam maior mobilidade intergeracional educacional.

Palavras-chave: Capital humano. Oferta educacional. Mobilidade intergeracional educacional.

\begin{abstract}
The study aims to assess the supply of public education in primary and secondary education from Brazilian micro-regions in the period 2000 and 2010, and investigate its relationship with educational intergenerational mobility. Therefore, employs two strategies are applied to empirical data from the school census and demographic censuses. In the first, via the Data envelopment analysis, was estimated coverage education (ICE) based approach Junoy-Puig (1999). The results suggest that the level of coverage of high school education both as fundamental showed an improvement during the study period. The second aims to apply an econometric model grounded in Ferreira and Veloso (2003), which suggests that in micro-regions with higher efficiency as the public provision of education have higher educational intergenerational mobility.
\end{abstract}

Keywords: Human capital. educational supply. Intergenerational educational mobility.

JEL Classification: I240; J620; C670.

\footnotetext{
* $\quad$ Doutoranda em Economia pela Universidade Federal da Paraíba (UFPB). Analista de Controle Externo do Tribunal de Contas do Estado do Acre (TCE/AC). E-mail: nandinha.economia@gmail. com

** $\quad$ Doutor em Economia Aplicada pela Universidade Federal do Rio Grande do Sul (UFRGS). Professor do Programa de Pós-Graduação em Economia (PPGE) da Universidade Federal da Paraíba (UFPB).E-mail: juniorluis@yahoo.com
} 


\section{1 lntrodução}

Há uma vasta literatura que reconhece a acumulação de capital humano como fator determinante na explicação dos diferenciais de nível de renda e, portanto, fundamentais quanto à elaboração de políticas econômicas e sociais. Tais políticas têm como base modelos teóricos que sugerem uma associação forte entre nível educacional e rendimento (MINCER, 1958, 1974; SCHULTZ, 1960, 1975; BECKER, 1964; LUCAS, 1988; BARRO; LEE, 2000). Nesse debate, vale ressaltar o estudo de Mankiw, Romer e Weil (1992), que apresenta uma ampliação do modelo de Solow incluindo capital humano, no qual destaca o seu papel como relevante para o nível de renda per capita das economias.

Além disso, vários trabalhos transcendem o reconhecimento da importância do capital humano e investigam os fatores que influenciam a sua acumulação. Entre diversos fatores, destacam-se aqueles relacionados ao ambiente escolar e aqueles relacionados ao ambiente familiar (background familiar): o primeiro está relacionado à oferta educacional (BRUNELLO; CHECCHI, 2006), em termos tanto de sua disponibilidade, quando de sua qualidade; e o segundo, por sua vez, está relacionado à caracterização da demanda (AAKVIK; VAAGE; SALVANES, 2005; ERMISCH; FRANCESCONI, 2001, 2004), em particular na importância do ambiente familiar na determinação da escolaridade dos filhos.

De acordo com Riani e Rios-Neto (2008), o debate acerca desses dois fatores já está bem avançado em países desenvolvidos, ${ }^{1}$ ao contrário do que acontece nos países em desenvolvimento. No entanto, vale ressaltar que, apesar dessa abordagem ser recente, grande parte dos estudos sugere que os fatores familiares são de extrema importância na explicação dos determinantes do nível escolar, contudo os fatores associados ao ambiente escolar não podem ser desprezados no tocante à acumulação de capital humano.

No Brasil, existe uma gama de estudos cujo objetivo é analisar de que forma a família impacta na educação dos filhos (LAM, 1999; BARROS et al., 2001; FERREIRA; VELOSO, 2003; FIGUEIREDO; NETTO JÚNIOR, 2009). No entanto, estudos recentes de Barros et al. (2001), Riani, Cézar e Rios-Neto (2002) e Riani e Rios-Neto (2008) incluem, além dos fatores familiares, variáveis relacionadas à escola e ao ambiente comunitário e concluem que esses fatores também produzem grande efeito.

Esta pesquisa parte do pressuposto de que a decisão de investir em capital humano é influenciada pelo background familiar (efeito local) e pelas condições externas (efeito externo) oriundas de um sistema educacional mais equitativo. Entende-se que pode haver uma sobreposição desses efeitos dependendo do perfil

$1 \quad$ Ver Lee e Barro (2001). 
educacional da família e do local em que esta reside. Não obstante, uma questão bem importante, e muitas vezes pouco explorada na literatura, é a de que os dois efeitos podem agir simultaneamente, ou seja, a disponibilidade de educação e o background familiar podem interagir na produção de capital humano individual. É justamente nesse ponto que a pesquisa avança, pois se mede o impacto dos fatores escolares, tratados como maior disponibilidade dos serviços educacionais, sobre a educação dos filhos na medida em que estes se encontram localizados em regiões eficientes ou não em ofertar educação pública.

Do ponto de vista metodológico, este estudo difere dos demais trabalhos ao propor os fatores escolares sob o prisma de cobertura educacional. Através de data envelope analysis (DEA) e de um conjunto de insumos e produtos, propõe-se um indicador ${ }^{2}$ (sintético) que permite apontar as localizações de maior déficit educacional, bem como as que se apresentarem eficientes quanto à oferta. Em linhas gerais, a presente pesquisa tem como objetivo avaliar a oferta de serviços públicos educacionais no ensino fundamental e médio das microrregiões brasileiras de 2000 e 2010 e investigar suas relações com a mobilidade intergeracional educacional no Brasil.

Como já mencionado, muitos trabalhos têm abordado a influência dos fatores escolares e do background familiar. No entanto, o presente estudo dá especial ênfase ao campo dos fatores externos, ou relacionados ao ambiente, no que se refere à mobilidade intergeracional educacional. Desse modo, os esforços metodológicos são voltados para a mensuração da oferta de serviços educacionais e seus impactos no tocante à dinâmica educacional.

O artigo encontra-se dividido em cinco seções, incluindo esta introdução: a segunda traz uma revisão da literatura sobre os fatores que influenciam a acumulação de capital humano; a terceira apresenta os procedimentos metodológicos; a quarta faz uma análise empírica do índice de cobertura educacional (ICE) e das investigações sobre seu impacto na mobilidade intergeracional educacional; e, por fim, a quinta traça as considerações finais.

\section{Revisão da Literatura}

O início do debate acerca do crescimento econômico desenvolveu-se durante a década de 1950 com o surgimento do modelo de Solow (1956), o qual dá suporte às novas teorias neoclássicas que enfatizam o papel do capital humano na explicação sobre os diferenciais de rendimento das economias. Jones (2000) alega que os dois artigos de Solow $(1956,1957)$ ajudam a entender o papel da acumu-

2 Atualmente existem vários indicadores educacionais, como, por exemplo, a taxa de analfabetismo e a taxa bruta de escolarização, entre outros. Contudo, alguns indicadores existentes limitam-se a retratar características específicas da educação através de relações estatísticas que não têm o poder de incorporar várias dimensões à análise. 
lação de capital físico e do progresso tecnológico como motor do crescimento econômico sustentado.

\subsection{A Importância do Capital Humano}

As relações entre o desenvolvimento dos recursos humanos e o crescimento econômico desenvolveram-se mais intensamente na década de 1960, sobretudo com o trabalho de Theodore Schultz (1961). A partir desse ponto, muitos trabalhos passaram a incorporar o investimento em capital humano nas discussões de crescimento econômico, bem como se despertaram as questões microeconômicas dessa relação. Dessa forma, autores como Mincer $(1958,1974)$ passaram a investigar a relação entre o investimento na formação do trabalhador e a distribuição de renda pessoal. Em seus trabalhos, o Mincer chegou à conclusão de que existe uma correlação positiva entre essas duas variáveis. Do mesmo modo, Schultz (1975) investigou o valor econômico da educação. Contudo, apesar do enfoque microeconômico dado aos modelos, tanto Mincer quanto Schultz se deparam com a limitação dos rendimentos serem decrescentes, implicando alto grau de retornos em regiões menos favorecidas de capital.

A implicação de rendimento marginal decrescente imprimiu aos modelos certa subjetividade corroborada pela falta de evidência empírica das pesquisas. As implicações de convergência entre países ricos e pobres, como também a interrupção do crescimento no longo prazo, enfraqueceu a chamada escola mainstream. Mais tarde, Romer (1986, 1990), Lucas (1988), entre outros, incorporam o capital humano como uma variável de crescimento endógeno, sublinhando essa variável como fonte de crescimento constante. O desenvolvimento da nova teoria de crescimento econômico incrementou o modelo de Solow (1956) com novos conceitos, assim definidos: capital humano, learning-by-doing e pesquisa e desenvolvimento.

Dentro desse enlace, os estudos considerados como teorias de crescimento endógeno têm crescido fortemente sob a sustentação de rendimentos crescentes de escala, sendo geradas por externalidades via atuação do mercado, ou via nível de educação dos indivíduos. Romer (1990) destaca o papel do capital humano através da importância de novas ideias e novas tecnologias. Para Romer (1990), a importância do capital humano está na agregação que ele denota ao capital físico para o crescimento econômico dos países. Lucas (1988), por sua vez, combinando a teoria de Schultz e do modelo de Solow, bem como a de Becker, estabelece um modelo enfatizando a acumulação de capital humano pela educação e através da aprendizagem pela prática. Ao introduzir o capital humano no modelo, no sentido de mostrar como os níveis de capital humano afetam a produção e a forma como 
a alocação do tempo afeta sua acumulação, o autor chega às mesmas conclusões do modelo de Solow.

Nesse rol de discussões acerca das teorias de crescimento endógeno, Mankiw, Romer e Weil (1992) apresentam uma ampliação do modelo de Solow incluindo o capital humano. Esse artigo é considerado uma das principais contribuições à teoria neoclássica moderna. A conclusão dos autores é a de que a adição do capital humano fomenta a acumulação de capital humano como papel relevante na explicação dos diferenciais de rendimento. Em uma linha mais recente, Barro e Lee (2010) atualizam os dados de Mankiw, Romer e Weil (1992) e chegam aos mesmos resultados destes últimos.

\subsection{Background Familiar e Mobilidade Intergeracional Educacional}

As pesquisas sobre mobilidade, sobretudo a mobilidade intergeracional, vêm se fortificando cada vez mais na literatura. As primeiras contribuições dos estudos são de Becker e Tomes (1979), que investigam as relações de pais e filhos baseadas num modelo de maximização de utilidade. A ideia do modelo é que os indivíduos são altruístas, de modo que tanto o consumo quanto o rendimento do pai é afetado por choques que possam ocorrer com seus filhos.

Nas análises sobre a influência do background familiar no estoque de capital humano, o estudo da mobilidade intergeracional é importante para sua determinação, pois implica uma maior correlação entre o nível escolar dos indivíduos e de seus pais. Além disso, evidências empíricas enfatizam o estudo da mobilidade intergeracional educacional como um indicador de oportunidades, sugerindo a importância da educação na determinação da eficiência de capital humano ao argumentarem que os indivíduos com melhores níveis educacionais tendem a angariar melhores chances de ascensão social e econômica.

Dentro desse contexto, Behrman, Gaviria e Székely (2001) realizam um estudo sobre a mobilidade intergeracional nos países da América Latina. ${ }^{3} \mathrm{~A}$ ideia é saber se a desigualdade é impulsionada principalmente pela ausência de oportunidades decorrente do background familiar ou pelas diferenças nas características individuais. Outros estudos semelhantes realizados são o de Balsmeier e Peters (2008), para alunos do ensino médio da Alemanha, no período de 2000 a 2007, e o de Aakvic, Vaage e Salvanes (2005) analisam o efeito de aspectos de contexto familiar, tais como renda familiar e escolaridade dos pais, sobre o nível de escolaridade de pessoas nascidas na Noruega.

3 Pela dificuldade na obtenção de dados, o trabalho concentrou-se nos seguintes países: Brasil, Colômbia, México e Peru. 
Birchenall (2001), a partir dos estudos de Galor e Tsiddon (1997), ${ }^{4}$ analisa a relação entre crescimento econômico e capital humano na Colômbia. A análise demonstra que as inter-relações da desigualdade dependem das características individuais e dos incentivos agregados da educação. $\mathrm{O}$ autor pressupõe a existência de um equilíbrio intergeracional no qual o estoque de capital humano é decorrente da relação entre background familiar e o ambiente global em que está inserida a família. Logo, em economias marcadas por grandes mudanças estruturais, como a de abertura econômica, gera-se um incentivo para se continuar a acumular capital humano.

Nessa mesma linha, destacam-se trabalhos que analisam o caso brasileiro, como os de Figueirêdo, Netto Júnior e Porto Júnior (2007) e Netto Júnior e Figueiredo (2009) ao mostrarem que houve forte aumento do grau mobilidade de renda e educacional no Brasil, acompanhado por uma polarização da renda. Figueirêdo, Netto Júnior e Porto Júnior (2007) investigam a natureza das mudanças ocorridas no período de 1987 a 2003, através de uma série de instrumentais estáticos e dinâmicos, e ratificam a teoria de Bichenall (2001) de que em cenários nos quais há um efeito tecnológico ocorrem um decréscimo do efeito familiar. Por sua vez, Netto Júnior e Figueiredo (2009) analisam os ritmos de acumulação de capital humano através do censo demográfico de 2000 e a mobilidade intrageracional de renda de 1995 a 2005.

Adiciona-se a esse rol, o trabalho de Netto Júnior, Ramalho e Aragon (2010) ao sugerir que atributos biparamentais também têm peso importante para a determinação da renda dos filhos. Para isso, os autores analisam os determinantes da mobilidade intergeracional de renda e investigam suas relações com a dinâmica intergeracional educacional tendo como base os dados dos censos demográficos de 1991 e 2000.

Além dos trabalhos mencionados, um dos estudos de maior destaque ao investigar mobilidade educacional para o Brasil é o de Ferreira e Veloso (2003), no qual apresentam evidências detalhadas sobre mobilidade intergeracional de educação com base no suplemento da PNAD de 1996. O principal resultado é o de que a persistência intergeracional de educação é significativamente mais elevada entre filhos de pais com baixa escolaridade que entre filhos de pais com maior escolaridade.

Ceroni (2000) desenvolve um modelo de gerações sobrepostas enfatizando o capital humano como único fator de produção em uma economia financiada pelo setor privado. Quando jovens, os agentes podem receber uma educação que determina o capital humano e a renda quando velho. A principal implicação são as

$4 \quad$ Galor e Tsiddon (1997) apresentam efeitos positivos intrafamiliares externos na produção de capital humano e situações de estudo em que as diferenças nas habilidades e na renda entre as famílias podem ser passadas de uma geração para a seguinte. 
armadilhas da pobreza, em que os pobres tendem a continuar pobres pela falta de rendimentos para investir na educação. Com a introdução de um sistema público de educação constata-se a redução das desigualdades de renda no curto prazo.

Por outro lado, o artigo de Checchi, Ichino e Rustichini (1999) mostra que a Itália apresentou uma baixa mobilidade intergeracional educacional mesmo tendo um sistema educacional igualitário com custos menores do que os dos Estados Unidos. Isso é explicado em decorrência da alta persistência dos efeitos dos pais associados à baixa sensibilidade aos choques externos da Itália. Em contrapartida, Chevalier, Deny e MsMahon (2003) afirmam que países com sistemas educacionais igualitários também desfrutam de uma maior mobilidade.

\subsection{Fatores Escolares: Oferta Educacional}

De acordo com Brunello e Checchi (2006), o contexto familiar tem influência nos resultados escolares, bem como tem implicações na eficiência e na equidade. Para os autores, limitações quanto ao acesso à educação podem estar associadas a restrições de créditos e a antecedentes familiares. Tais fatores podem reduzir o investimento em educação abaixo do nível eficiente (BARROS et al., 2001). As evidências empíricas encontradas pelos autores, baseadas nos estudos de países, acolhem a ideia de que restrições de ensino reforçam a persistência intergeracional no desempenho escolar. Além disso, essas restrições aumentam as desigualdades educacionais, gerando impacto negativo para a igualdade de oportunidades.

Barros et al. (2001) também chama atenção para as restrições de crédito, salientando que o investimento em capital humano é particularmente sensível às assimetrias desse mercado. Além disso, enfatizam que os acréscimos de investimento em educação são induzidos pela redução das imperfeições desse mercado, ou mesmo pelo aumento das taxas de retornos desse investimento. A partir desses pressupostos, os autores investigam alguns fatores relacionados à demanda por educação e outros relacionados à oferta.

Os fatores relacionais a demanda, particularmente a mobilidade intergeracional educacional, foram discutidos na subseção anterior. Por sua vez, os fatores relacionados à oferta compreendem a economia da educação e têm por objetivo apontar os insumos mais importantes na determinação dos resultados do sistema educativo de uma região. De acordo com Riani e Rios-Neto (2008), esses fatores abrangem questões do ambiente escolar em termos tanto da sua disponibilidade, quanto de sua qualidade, e normalmente seus efeitos seriam minimizar o impacto da família no resultado educacional do indivíduo.

Através da estimação da função de produção de educação, muitas pesquisas têm sido realizadas com o intuito de medir o impacto desses fatores sobre o desempenho escolar dos indivíduos, sobretudo dos desempenhos dos testes padroni- 
zados, como o Sistema de Avaliação da Educação Básica (Saeb) e a Prova Brasil. A forma geral da função de produção educacional é dada pela seguinte equação:

$$
Y=F(c, m, g, p, s)
$$

em que $Y$ é o desempenho dos alunos; $c$ é as características pessoais dos alunos, como raça e gênero; $m$ é as características de suas famílias, como renda ou outra medida de seu nível socioeconômico; g é as características de seus colegas de escola; $p$ é as características de seus professores, como escolaridade, salário e experiência; e $s$ representa outras características escolares. Conforme Waltemberg (2006), a incorporação da oferta da educação, estimada na equação 1, determina a tecnologia de produção da educação à disposição das escolas. Desse modo, é possível obter a fronteira de possibilidades de produção de educação, ou seja, através da combinação de insumos é possível determinar as escolas mais eficientes, bem como estabelecer as melhores combinações de insumos desejáveis para a provisão eficiente dos serviços educacionais.

A partir desse modelo, o trabalho de Albernaz, Ferreira e Franco (2002) estima a função de produção educacional para o ensino fundamental através de um modelo linear hierárquico, utilizando como base de dados o Saeb para as oitavas séries de 1999. A conclusão dos autores é a de que cerca de $80 \%$ da variância do desempenho médio entre as escolas deve-se a diferenças na composição socioeconômica de seus alunos. Esses autores apontam que fatores como a escolaridade dos professores e a qualidade da infraestrutura física também afetam o desempenho dos estudantes.

Em complemento, Riani e Rios-Neto (2008) pesquisam o quanto a qualidade da escola e de seus docentes pode diminuir a estratificação educacional existente no Brasil, investigando os determinantes do resultado educacional nos níveis de ensino fundamental e médio no país. Os resultados apontam duas importantes implicações: a) primeiro, que fatores escolares, principalmente os relacionados à qualidade dos recursos humanos e à infraestrutura dos serviços, aumentam o desempenho escolar; e b) segundo, que há um efeito de substituição entre fatores familiares e de oferta.

Apesar dos avanços nos estudos, principalmente pela sofisticação dos modelos e indicadores utilizados nas pesquisas recentes, os modelos de função de produção de educação sempre se depararam com limitações de duas naturezas, conforme aponta Waltenberg (2006). A primeira concerne ao lado esquerdo da equação 1 - o produto do sistema (output), do qual se buscava entender qual era o objetivo geral que se pretendia investigar. Definir a variável dependente tratava-se em definir esse objetivo, e, por vezes, a escolha de apenas uma variável 
representativa do objetivo assinalava limites com fortes implicações para políticas públicas.

Além disso, medir desempenho escolar através de testes padronizados impediam países como, por exemplo o Brasil, de utilizá-lo uma vez que até pouco tempo atrás não possuíam indicadores dessa dimensão. A segunda natureza diz respeito ao lado direito da equação 1 , no que tange à escolha das variáveis representativas de recursos (inputs). Uma hipótese desses estudos era a de que, sendo o processo educativo semelhante à produção de outros bens, um aumento dos recursos injetados na produção (insumos) deveria conduzir a um aumento do produto (output) (WALTENBERG, 2006). Uma relação que até nos dias atuais gera um grande debate na economia da educação.

\section{Procedimentos Metodológicos}

\subsection{Descrição dos Dados}

O ICE foi obtido tendo como base os dados do censo escolar ${ }^{5}$ do Instituto Nacional de Estudos e Pesquisas Educacionais Anísio Teixeira (Inep) e do censo demográfico do Instituto Brasileiro de Geografia e Estatística (IBGE) dos anos de 2000 e 2010. Foram consideradas 558 observações correspondentes às microrregiões brasileiras que compuseram as unidades de tomada de decisão (decision making units - DMU).

A partir dessas duas bases de dados, e com o objetivo de obter um conjunto de oferta (atendimento) frente a um conjunto de necessidades semelhantes (demanda potencial), foram coletadas as informações sintetizadas no Quadro 1. A escolha dessas variáveis tomou como referência, guardadas as devidas adaptações, ${ }^{6}$ as utilizadas por diversos autores, dentre o quais se destacam: Lee e Barro (2001), Barros et al. (2001), Riani, Cézar e Rios-Neto (2002), Sampaio de Sousa e Stösic (2005a, 2005b) e Riani e Rios-Neto (2008), entre outros.

$\overline{5}$ O censo escolar é um dos levantamentos estatístico-educacionais realizados pelo Inep, abrangendo a educação básica em diferentes níveis: infantil, fundamental e médio. Além disso, abrange também a educação regular, a educação especial e a educação de jovens e adultos.

6

Alguns autores utilizaram variáveis representativas da oferta e demanda por educação, mas com metodologias diferentes. 
Quadro 1 - Descrição das variáveis para a construção do ICE

\begin{tabular}{|c|c|c|c|c|c|}
\hline \multicolumn{6}{|c|}{ Variáveis da fronteira de melhor disponibilidade } \\
\hline \multicolumn{3}{|c|}{ Input (necessidades) } & \multicolumn{3}{|c|}{ Output (atendimento) } \\
\hline Variável & Descrição & $\begin{array}{l}\text { Especifi- } \\
\text { cação }\end{array}$ & Variável & Descrição & Especificação \\
\hline \multirow[b]{2}{*}{$\begin{array}{l}\text { Aban- } \\
\text { dono }\end{array}$} & \multirow[b]{2}{*}{$\begin{array}{l}\text { Número de } \\
\text { abandonos }\end{array}$} & \multirow{2}{*}{$\begin{array}{l}\text { Alunos da } \\
\text { matrícula } \\
\text { total na } \\
\text { série k, no } \\
\text { ano t, que } \\
\text { aban- } \\
\text { donam a } \\
\text { escola. }\end{array}$} & $\begin{array}{l}\text { Estabel- } \\
\text { ecimen- } \\
\text { tos }\end{array}$ & $\begin{array}{l}\text { Número } \\
\text { de esta- } \\
\text { beleci- } \\
\text { mentos }\end{array}$ & $\begin{array}{c}\text { Escola (esta- } \\
\text { belecimento) } \\
\text { pode funcionar } \\
\text { em mais de um } \\
\text { prédio. }\end{array}$ \\
\hline & & & $\begin{array}{l}\text { Matricu- } \\
\text { lados }\end{array}$ & $\begin{array}{l}\text { Número } \\
\text { de ma- } \\
\text { triculados }\end{array}$ & $\begin{array}{c}\text { Matrícula inicial } \\
+ \text { admitidos - } \\
\text { transferidos + } \\
\text { reclassificados } \\
\text { admitidos - } \\
\text { reclassificados } \\
\text { transferidos, na } \\
\text { série k, no ano t. }\end{array}$ \\
\hline \multirow[t]{2}{*}{$\begin{array}{l}\text { Repro- } \\
\text { vado }\end{array}$} & \multirow[t]{2}{*}{$\begin{array}{l}\text { Número de } \\
\text { reprovados }\end{array}$} & \multirow{2}{*}{$\begin{array}{c}\text { Quanti- } \\
\text { dade de } \\
\text { alunos da } \\
\text { matrícula } \\
\text { total na } \\
\text { série } k \text {, no } \\
\text { ano } t \text {, que } \\
\text { se matricu- } \\
\text { la na série } \\
\text { k, no ano } \\
\text { t+1. }\end{array}$} & $\begin{array}{l}\text { Do- } \\
\text { centes } \\
\text { qualifica- } \\
\text { dos }\end{array}$ & $\begin{array}{l}\text { Número } \\
\text { de do- } \\
\text { centes } \\
\text { com licen- } \\
\text { ciatura }\end{array}$ & $\begin{array}{c}\text { Professores com } \\
\text { licenciatura que } \\
\text { estão atuando } \\
\text { em sala de } \\
\text { aula, mas que } \\
\text { podem atuar em } \\
\text { outras escolas } \\
\text { ou outros níveis } \\
\text { educacionais. }\end{array}$ \\
\hline & & & $\begin{array}{l}\text { Aprova- } \\
\text { dos }\end{array}$ & $\begin{array}{c}\text { Número } \\
\text { de apro- } \\
\text { vados }\end{array}$ & $\begin{array}{c}\text { Alunos da } \\
\text { matrícula total } \\
\text { na série } \mathrm{k} \text {, no } \\
\text { ano t, que foram } \\
\text { aprovados. }\end{array}$ \\
\hline $\mathrm{Pop}_{1}$ & $\begin{array}{c}\text { População } \\
\text { apta ao } \\
\text { serviço }\end{array}$ & $\begin{array}{l}\text { Indivíduos } \\
\text { com idade } \\
\text { escolar que } \\
\text { moram nas } \\
\text { micror- } \\
\text { regiões. }\end{array}$ & $\begin{array}{c}\text { Fun- } \\
\text { cionários }\end{array}$ & $\begin{array}{l}\text { Número } \\
\text { de fun- } \\
\text { cionários }\end{array}$ & $\begin{array}{l}\text { Quantidade de } \\
\text { funcionários nos } \\
\text { estabelecimen- } \\
\text { tos. }\end{array}$ \\
\hline
\end{tabular}

Fonte: Elaboração própria.

Nota: ${ }^{1}$ População de 7 a 14 anos para o ensino fundamental e população de 15 a 17 anos para o ensino médio. 
No que tange às variáveis representativas do vetor inputs (necessidade), consideraram-se as variáveis de dependência pública e localizadas em áreas urbanas e rurais. Esse vetor caracteriza-se por apresentar os principais fatores que geram demanda pelos serviços educacionais. Para o vetor outputs (atendimento), consideraram-se, também, as variáveis da dependência pública (excluindo-se os particulares) e localizadas nas áreas urbanas e rurais.

A segunda estratégia empírica utilizada neste artigo leva a dois métodos: a) correlação de Spearman; e b) abordagem econométrica. Para os dois métodos, utilizou-se a variável "anos de estudos", oriunda do censo demográfico de 2000, com recortes de idade (7 a 14 - fundamental; 15 a 17 - médio). Contudo, para se obter dados da pessoa referência, pai e seus filhos, foi necessário unificar7 a base de dados "domicílio" e de "pessoa”, conforme descrito em Netto Júnior, Ramalho e Aragon (2010).

Para os propósitos da estimação da correlação de Speraman, calculou-se, a partir das informações relativas a anos de estudos de pais e seus filhos oriundos do censo demográfico de 2000, a persistência intergeracional educacional dos pais analfabetos (sem instrução) sobre seus filhos para cada microrregião, guardados os recortes de idade dos filhos de cada estrato educacional. Outra importante variável é o éndice de Gini educacional de todas as microrregiões. A ideia é a de que essa metodologia reflita as desigualdades educacionais existentes entre as microrregiões brasileiras e, com isso, possa ser utilizada para inferir sobre a correlação entre estas e a disponibilidade dos serviços públicos educacionais (ICE). A estimação do índice de Gini educacional ${ }^{8}$ foi baseada na metodologia de Thomas, Wang e Fan (2000) a partir dos dados do censo demográfico de 2000 .

\subsection{Primeira Estratégia Empírica: Análise Envoltória de Dados (DEA)}

A análise envoltória de dados (DEA), método não paramétrico, é uma ferramenta matemática baseada em programação linear que compara certo número de observações para estimar a fronteira de possibilidades de produção. Essa técnica proveniente do trabalho seminal de Farrel (1957), e amplamente divulgada por Charnes, Cooper e Rhodes (1978), pressupõe a existência de uma fronteira de produção linear ou convexa, permitindo o cálculo de medidas de eficiência técnica. Destarte, esses autores são reconhecidos na literatura como os percussores do

7 De acordo com Netto Júnior, Ramalho e Aragon (2010), a unificação é possível devido à própria metodologia do censo demográfico, em que, para cada domicílio, há um responsável (chefe).

$8 \quad \mathrm{O}$ cálculo do índice é dado por $\mathrm{G}^{\mathrm{E}}=1 / \mu \mathrm{N}(\mathrm{N}-1) \sum_{\mathrm{i}>\mathrm{j}} \sum_{\mathrm{i}}\left|\mathrm{y}_{\mathrm{i}}-\mathrm{y}_{\mathrm{i}}\right|$, alternativa da expressão $\mathrm{G}^{\mathrm{E}}=(1 / \mu) \sum_{\mathrm{i}=2}^{\mathrm{n}} \sum_{\mathrm{j}=1}^{\mathrm{i}-1} \mathrm{p}_{\mathrm{i}}\left|\mathrm{y}_{\mathrm{i}}-\mathrm{y}_{\mathrm{j}}\right| \mathrm{p}_{\mathrm{j}}$, em que $\mathrm{G}^{\mathrm{E}}$ é o índice de Gini educacional; $\mu$ é a média de escolaridade; $\mathrm{p}_{\mathrm{i}}$ e $\mathrm{p}_{\mathrm{i}}$ são as proporções da população com certo nível de escolaridade; $\mathrm{y}_{\mathrm{i}}$ e $\mathrm{y}_{\mathrm{i}}$ são os anos de escolaridade; e n é o número de níveis do ciclo educacional. Optou-se por essa opção porque a variável anos de estudos do censo demográfico é uma variável discreta com limite inferior (zero) e limite superior (17) (BAGOLIN; PORTO JÚNIOR, 2003). 
método devido à sua formalização para múltiplos insumos e produtos, diferindo de Farrel (1958), que utiliza apenas um insumo e um produto.

Charnes, Cooper e Rhodes (1978) desenvolveram o que veio a ser chamado de modelo DEA-CCR, em alusão às iniciais dos autores. Esse modelo, também denominado de DEA-CRS, em referência à constant returns of scale, trabalha com retornos constantes de escala, ou seja, qualquer variação nos insumos produz variação proporcional nos produtos. Ferreira e Gomes (2009) afirmam que o método determina a eficiência técnica pela otimização da divisão entre soma ponderada dos produtos e a soma ponderada dos insumos, formalmente:

$$
h_{0}=\frac{\sum_{j=1}^{m} u_{j} y_{j 0}}{\sum_{i=1}^{r} v_{i} x_{i o}}=\frac{u_{1} y_{1 o}+u_{2} y_{2 o}+\cdots+u_{m} y_{m o}}{v_{1} x_{1 o}+v_{2} x_{2 o}+\cdots+v_{r} x_{r o}}=\frac{\text { produto virtual }}{\text { insumo virtual }}
$$

em que: $h_{0}$ é a taxa de eficiência relativa da $\mathrm{DMU}_{0} ; \mathrm{y}_{\mathrm{j} 0}$ é a quantidade de output, observado o $j$ da unidade $m$; $x_{i 0}$ é a quantidade de input, observado o $i$ da unidade $r$; $u_{\mathrm{j}}$ é a variável de decisão que representa o peso dado ao output m; e v é a variável de decisão que representa o peso dado ao input $r$.

A formulação 2 pressupõe pesos iguais para todas as DMUs. Seu objetivo é determinar os pesos $u_{j}$ e $v_{i}$, a fim de maximizar a programação matemática fracionária $(\mathrm{PMF})$, de forma que cada $\mathrm{DMU}_{0}$ possa ter pesos diferentes, como também valores de insumos e produtos diferentes, de modo que a diferença de pesos possa ser mais favorável a uma quando comparados a outras DMUs. Logo, a PMF será:

$$
\begin{gathered}
\max _{(u, v)} h_{0}=\sum_{j=1}^{m} u_{j} y_{j 0} \\
\text { Sujeito a: } \sum_{i=1}^{r} v_{i} x_{i 0}=1 ; \quad \sum_{j=1}^{m} u_{j} y_{j 0}-\sum_{i=1}^{r} v_{i} x_{i 0} \leq 0, \forall k ; \quad u_{j}, v_{i} \geq 0, \forall i, j
\end{gathered}
$$

A solução ótima obtida, ou seja, as DMUs que possuem coeficiente igual à unidade, são chamadas de Pareto-Koopmans ${ }^{9}$ eficientes, se e somente, se nenhum de seus insumos ou produtos puder ser melhorado sem piorar alguns de seus outros insumos e produtos. De acordo com Ferreira e Gomes (2009), essa definição pressupõe que se conheça a priori a eficiência 100\%. Na prática, os níveis de eficiência são normalmente desconhecidos, fazendo com que essa definição seja substituída por eficiência relativa, ou seja, serão eficientes, se e somente, se os desempenhos de outras DMUs do conjunto em análise não demonstrarem que alguns de seus insumos ou produtos da $\mathrm{DMU}_{0}$ podem ser melhorados (FERREIRA; GOMES, 2009).

Esse nome é devido às contribuições de Vilfredo Pareto (1848-1923), com a lei de Pareto, ou ótimo de Pareto, e de Tjalling C. Koopmans (1910-1985), com o princípio da eficiência produtiva. 
Mais tarde, Bankers, Charnes e Cooper (1984) propuseram um modelo para trabalhar com retornos variáveis de escala considerando tecnologias com rendimentos de escala constantes, crescentes e decrescentes. O modelo ficou conhecido com DEA-BCC (acrônimo formado pelas iniciais dos autores) ou DEA-VRS (em referência à variable returns to scale). A grosso modo, o modelo DEA-BCC difere do DEA-CCR pelo fato de que o modelo BCC troca o axioma da proporcionalidade entre inputs e outputs pelo axioma da convexidade.

Formalmente, o nível de eficiência de cada DMU é obtido resolvendo o seguinte problema de programação linear: ${ }^{10}$

$$
\max _{(u, v)} h_{0}=\sum_{j=1}^{m} u_{j} y_{j 0}+u_{o}
$$

Sujeito a: $\sum_{i=1}^{r} v_{i} x_{i 0}=1 ; \quad \sum_{j=1}^{m} u_{j} y_{j 0}-\sum_{i=1}^{r} v_{i} x_{i k}+u_{0} \leq 0, \quad \forall k ; \quad \sum_{k=1}^{n} \lambda_{k}=1 ; u_{j}, v_{i} \geq$

$$
0(\varepsilon), \quad \forall i, j
$$

É possível perceber que a equação 3 difere da equação 4 pela inclusão de uma restrição adicional chamada de restrição de convexidade: $\sum_{\mathrm{k}=1}^{\mathrm{n}} \lambda_{\mathrm{k}}=1$.

\subsubsection{Fronteiras de Melhor Disponibilidade Relativa para as Mesmas Necessidades}

Esta pesquisa utiliza a abordagem proposta por Puig-Junoy (1999) para a construção da fronteira de disponibilidade de serviços públicos educacionais para as microrregiões brasileiras, permitindo inferir sobre o nível de cobertura desses serviços. Essa abordagem tem como base a noção de equidade, o que representa um forte instrumento para a construção de indicadores não paramétricos.

A eficiência está associada à igualdade de acesso para necessidades semelhantes. Nesse contexto, as DMUs são caracterizadas pela oferta de um conjunto de serviços educacionais representado por $\mathrm{y}_{\mathrm{j}}=\left(\mathrm{y}_{\mathrm{j} 1}, \ldots, \mathrm{y}_{\mathrm{jm}}\right)$ para atender a um conjunto de necessidades representadas por $\mathrm{x}_{\mathrm{i}}=\left(\mathrm{x}_{\mathrm{i} 1}, \ldots, \mathrm{x}_{\mathrm{ik}}\right)$. De acordo com Gasparini, Costa e Sampaio (2009), a avaliação sobre a prestação de serviços públicos deve considerar o conjunto de necessidades presentes em cada localidade, justificada pela grande diversidade no que se refere às demandas sociais. Então, obtêm-se os ICEs ao resolver o problema de programação linear:

$$
\begin{gathered}
\mathrm{F}_{0}=\max _{(\theta, \lambda)} \theta \\
\text { Sujeito a: } x_{i 0}-\sum_{k=1}^{n} x_{i k} \lambda_{k} \geq 0 \quad \forall i ; \sum_{k=1}^{n} y_{m k} \lambda_{k}-\theta y_{m 0} \geq 0 \forall m ; \sum_{k=1}^{n} \lambda_{k}=1
\end{gathered}
$$

10 Sendo que retornos constantes de escala (RCE) $\rightarrow$ acrescenta $\rightarrow \lambda_{k} \geq 0, \forall k=1,2, \ldots, n$.; rendimentos variáveis de escala (RVE) $\rightarrow$ acrescentar $\rightarrow \sum_{k=1}^{n} \lambda_{k}=1$; rendimentos não crescentes de escala $(\mathrm{RNC}) \rightarrow$ acrescentar $\rightarrow \sum_{\mathrm{k}=1}^{\mathrm{n}} \lambda_{\mathrm{k}} \leq 1$; e rendimentos não decrescentes de escala $(\mathrm{RND}) \rightarrow$ acrescenta $\rightarrow \sum_{\mathrm{k}=1}^{\mathrm{n}} \lambda_{\mathrm{k}} \geq 1$. 
A equação 5 considera rendimentos variáveis de escala em que $\mathrm{F}_{0}$ é o índice de eficiência. A inferência do escore dado por $\mathrm{F}_{0}$ denota três situações: a) quando $\mathrm{F}=1$, soma das folgas igual a zero, que significa que a microrregião se encontra na fronteira de melhor disponibilidade, ou seja, é eficiente na oferta relativa de serviços públicos educacionais; b) quando $\mathrm{F}=1$, mas apresentando soma das folgas diferentes de zero, representando que o município se encontra na fronteira, mas não constitui eficiente sob o ponto de vista eficiente Pareto-Koopmans; e quando c) F $>1$, que indica ineficiência da DMU na oferta e mede a proporção em que o vetor outputs deve ser aumentado para atingir a fronteira.

Em resumo, o modelo utilizado neste trabalho é orientado para outputs e supõe rendimentos variáveis ${ }^{11}$ de escala, sendo o grau de cobertura dos serviços dado por (1/F). A orientação para o atendimento dos serviços se deve ao objetivo do trabalho, que é alcançar os melhores índices de atendimento dos serviços a fim de apontar as microrregiões mais eficientes em ofertar serviços educacionais, além de elencar as deficitárias.

\subsubsection{Detecção de Outliers: Método Jackstrap}

Para atender a um dos objetivos, ou seja, estimar a fronteira de disponibilidade de serviços educacionais, através do DEA, para as 558 microrregiões brasileiras em dois anos, 2000 e 2010, deve-se observar que o método DEA é extremamente sensível à presença de outliers. De acordo com Puig-Junoy (1999), as medidas de disponibilidade não incluem explicitamente um termo de ruído, mas as medidas resultantes do DEA incorporam qualquer ruído estocástico na base de dados. Por sua vez, Stošić e Sousa (2003) ressaltam que a heterogeneidade dos conjuntos de dados pode subestimar, substancialmente, os escores de eficiência.

Para sanar esse problema, realizou-se o procedimento Jackstrap, desenvolvido por Sousa e Stošić (2005), que combina os regimes de reamostragem bootstrap e Jackknife para a seleção automática de outliers. A técnica baseia-se na construção de medidas de leverage a partir dos resultados oferecidos pelo DEA, assim, calcula-se a influência que cada observação produz em todas as demais. Parte-se do pressuposto que valores muito altos de alavancagem normalmente são observações outliers. O cálculo do leverage é obtido por

$$
l_{j}=\sqrt{\frac{\sum_{k=1 ; k \neq j}^{K}\left(\theta_{k j}^{*}-\theta_{k}\right)}{K-1}}
$$

11 A escolha pelos rendimentos variáveis de escala tem como fundamento as inúmeras diferenças existentes nos municípios brasileiros. 
em que: $k$ é o conjunto de unidades de análise de 1 a $\mathrm{K} ; \theta^{*}{ }_{\mathrm{kj}}$ é o conjunto de índices de eficiência calculados para todas as DMUs com alavancagem; e $\theta_{k}$ é o conjunto de índices de eficiência calculados para todas as DMUs.

De acordo com Sousa e Stošić (2005), o procedimento Jackstrap é composto por duas partes. A primeira visa aplicar a técnica de reamostragem Jacknife em três passos para calcular as medidas de alavancagens, assim definidas: a) selecionar aleatoriamente um subconjunto de L DMUs (normalmente $10 \%$ do K) e realizar o cálculo da equação 6 a fim de se obter um subconjunto de alavancagens $\tilde{l}_{\mathrm{k} 1}$, em que o índice $\mathrm{k}$ assume $L$ (selecionados aleatoriamente) os valores do conjunto $\{1,2, \ldots, K\}$; b) repete-se o passo a $B$ vezes, acumulando as informações do subconjunto de alavancagens $\tilde{l}_{\mathrm{kb}}$, em que $b=1,2, \ldots, B$ para todas as DMUs selecionadas aleatoriamente.

A escolha do $B$ deve ser suficientemente grande para que cada DMU deva ser selecionado em cerca de $n_{k}=B L / K$ vezes; e c) calcula-se a média de alavancagem para cada DMU como $\tilde{l}_{\mathrm{k}}^{\mathrm{k}}=\left(\sum_{\mathrm{b}=1}^{\mathrm{K}} \mathrm{l}_{\mathrm{kb}}\right) / \mathrm{n}_{\mathrm{k}}$ e alavancagem média global por $\tilde{l}$ $=\sum_{\mathrm{k}=1}^{\mathrm{K}} \tilde{l}_{\mathrm{K}} / \mathrm{K}$.

A segunda fase consiste em utilizar a técnica de reamostragem bootstrap para produzir intervalos de confiança usando as informações de alavancagem (calculadas na primeira fase) para reduzir a probabilidade de selecionar um outliers identificado no processo de reamostragem estocástica. Nessa fase, pode-se detectar os outliers através de dois critérios: a) usar um múltiplo da alavancagem média global $\left(\tilde{l}_{\mathrm{k}}\right)$, de forma que $\tilde{l}_{0}=c \tilde{l}$, para criar um limite no descarte da observação. Como regra geral, se estabelece um $\mathrm{c}=2$ ou $\mathrm{c}=3$, e, considerando que se der nulo, rejeita-se a observação. Então tem-se que:

$$
\tilde{l}_{0}=c \tilde{l} \quad \begin{cases}1, & \tilde{l}_{0}<c \tilde{l} \\ 0, & \tilde{l}_{0} \geq c \tilde{l}\end{cases}
$$

b) levar em conta a dimensão $K$ da amostra, partindo da distribuição heaviside step function, ${ }^{12}$ assim definida como:

$$
P\left(\tilde{l}_{k}\right) \quad \begin{cases}1, & \tilde{l}_{k}<\tilde{l} \log K \\ 0, & \tilde{l}_{k} \geq \tilde{l} \log K\end{cases}
$$

12 Sousa e Stošić (2005) programam esse esquema a partir das distribuições de probabilidade linear, inversa, exponencial e da heaviside step function. 
Devido ao tamanho da amostra - 558 microrregiões - utilizou-se o método Jackstrap ${ }^{13}$ para a detecção automática de outliers considerando o critério baseado na distribuição heaviside step function.

\subsection{Segunda Estratégia Empírica: Background Familiar}

\subsubsection{Correlação de Spearman}

O coeficiente da correlação de Spearman ( $\rho$ ) é um coeficiente não paramétrico que mede a intensidade da relação entre variáveis ordinais, ou seja, ao invés de utilizar o valor das observações, o coeficiente leva em consideração a ordem das observações. Desse modo, através de sua mensuração, objetiva-se medir a intensidade da relação entre a disponibilidade dos serviços públicos educacionais (ICE), obtida através do DEA, e a persistência intergeracional educacional dos pais analfabetos, alcançados pelas matrizes de transição de Markov. Além disso, busca-se medir a intensidade da relação do ICE com o índice de Gini educacional para retratar que o impacto de aumentos do ICE tende a reduzir desigualdades educacionais.

A vantagem de se utilizar esse coeficiente é que ele não é sensível à assimetria na distribuição e nem aos outliers, ou seja, o coeficiente não necessita que as duas populações sejam normais. O coeficiente é adimensional e situa-se no intervalo entre -1 e 1. O coeficiente de correlação de Spearman é calculado pela seguinte expressão:

$$
\rho=1-\frac{6 x \sum_{i=1}^{N} d_{i}^{2}}{N^{3}-N}
$$

A ideia é de que quanto mais próximo de 1, maior será a correlação positiva entre as variáveis. Por sua vez, quanto mais próximo de -1, maior será a correlação negativa entre as variáveis. Para um $n$ muito grande $(n \geq 10)$, a significância do coeficiente pode ser verificada aplicando-se o teste $t$ de Student com $n=2$ graus de liberdade, nas seguintes formas: $\mathrm{H}_{0}$, se $X$ e $Y$ não estão correlacionados; e $\mathrm{H}_{\mathrm{A}}$,se $X$ e $Y$ estão correlacionados.

13 Além desse método, existe um método mais simples, e comumente utilizados nos trabalhos com $\mathrm{DEA}$, que para tratar outliers elimina-se as observações que estejam a mais de dois desvios padrões $(2 \sigma)$ da média $(\mu)$ em qualquer das variáveis da amostra. 


\subsubsection{Modelo Econométrico}

Esta última parte da segunda estratégia empírica tem por objetivo investigar se locais mais eficientes na oferta pública educacional têm efeito na mobilidade intergeracional educacional. Parte-se do pressuposto de que a acumulação de capital humano é influenciada tanto por fatores familiares quanto também por fatores escolares. A maioria dos trabalhos no Brasil tem investigado os impactos do background familiar, sobretudo na importância da escolaridade do pai na determinação da escolaridade dos filhos. Contudo, pouco se tem explorado a oferta educacional nessa relação.

Baseado no modelo empregado por Ferreira e Veloso (2003), o modelo estimado é

$$
S_{f i}=\alpha+\beta S_{p i}+\delta_{m} L+\gamma_{n} F+\zeta_{k} P+\varepsilon_{i}
$$

em que: $\mathrm{S}_{\mathrm{fi}}$ representa a educação do filho na família $i$; $\mathrm{S}_{\mathrm{pi}}$ é a educação do pai na família $i ; \beta$ mede a persistência intergeracional educacional; $\varepsilon_{i}$ é o termo estocástico com $\in\left(\varepsilon_{\mathrm{i}}\right)=0 ; \in\left(\varepsilon_{\mathrm{i}}, \mathrm{S}_{\mathrm{pi}}\right)=0$ e $\in\left(\varepsilon_{\mathrm{i}}^{2}\right)=\sigma^{2}$; e $\alpha$ é o intercepto.

Cabe destacar que o modelo explorado neste trabalho acrescenta duas distinções importantes em relação ao realizado por Ferreira e Veloso (2003). A primeira consiste em fazer dois recortes na idade dos filhos. Assim, se considerou apenas os filhos de 7 a 14 anos para o ensino fundamental e os filhos de 15 a 17 anos para o ensino médio. A segunda, e mais importante, é a incorporação de dummies para indicar qualidades de três tipos de atributos: a) atributos de localização (L); b) atributos do filho (F); e c) atributos dos pais (P). ${ }^{14}$

As dummies consideradas no modelo foram: a) localização - regiões e ICE da microrregião; ${ }^{15}$ b) filho $(\mathrm{F})$ - raça e sexo; e c) pais $(\mathrm{P})$ - sexo e pais*local (dummy de interação). ${ }^{16}$

Em conformidade com o realizado por Ferreira e Veloso (2003), a escolha pelo método de mínimos quadrados ordinários (MQO) se deu pela vantagem deste fornecer uma medida sumária do grau de mobilidade intergeracional educacional, dado pelo seu grau de persistência. Além disso, foi possível inserir dummies

14 Os pais neste trabalho são retratados como a pessoa de referência do domicílio, podendo ser homem ou mulher.

15 Microrregiões consideradas ineficientes ou com baixa cobertura foram denotadas por 0, e as microrregiões eficientes e intermediárias assumiram os valores de referência, 1.

16 A variável binária "pais*local" consiste em identificar se o local em que o pai vive tem uma boa cobertura educacional ou não. Em termos práticos, associaram-se os anos de escolaridade do pai à localização em que vive, sendo 1 para locais eficientes e 0 para ineficientes. 
que caracterizaram o ambiente escolar dos filhos e pais, a fim de testar a hipótese explorada.

\section{Resultados}

\section{1 Índice de Cobertura Educacional (ICE)}

A Tabela 1 traz os resultados da detecção de outliers e a quantidade de DMUs analisada. Verifica-se que, tanto para o ensino fundamental, quanto para o ensino médio, a quantidade de outliers para cada ano não ultrapassou os 9\% da amostra, permitindo a obtenção de uma fração representativa das microrregiões para os dois anos analisados e seus respectivos estratos educacionais. Contudo, vale ressaltar que se optou por excluir as DMUs atípicas (tanto as detectadas em 2000, quanto em 2010) em toda a base de dados para torná-la mais homogênea, permitindo, assim, a comparabilidade dos resultados explorados.

Tabela 1 - Microrregiões analisadas e os outliers

\begin{tabular}{l|c|c|c|c}
\hline \multirow{2}{*}{\multicolumn{1}{c|}{ Especificação }} & \multicolumn{2}{c|}{ Ensino fundamental } & \multicolumn{2}{c}{ Ensino médio } \\
\cline { 2 - 5 } & $\mathbf{2 0 0 0}$ & $\mathbf{2 0 1 0}$ & $\mathbf{2 0 0 0}$ & $\mathbf{2 0 1 0}$ \\
\hline $\begin{array}{l}\text { Quantidade total de micro- } \\
\text { regiões }\end{array}$ & 558 & 558 & 558 & 558 \\
\hline Quantidade de outliers & 461 & 49 & 50 & 47 \\
\hline & $(8,24 \%)$ & $(8,78 \%)$ & $(8,96 \%)$ & $(7,88 \%)$ \\
\hline $\begin{array}{l}\text { Total de outliers em 2000 } \\
\text { e 2010 }\end{array}$ & \multicolumn{2}{|c|}{$83^{1}$} & \multicolumn{2}{c}{$81^{1}$} \\
\hline & \multicolumn{2}{c|}{$(14,87 \%)$} & \multicolumn{2}{c}{477} \\
\hline $\begin{array}{l}\text { Total de microrregiões } \\
\text { analisadas }\end{array}$ & 475 & & \\
\hline
\end{tabular}

Fonte: Elaboração própria.

Nota: No somatório não se contabilizam os outliers comuns nos dois anos de cada estrato.

No geral, para o ensino fundamental se procedeu à análise do ICE para 475 microrregiões e, para o ensino médio, para 477 , o que corresponde a $85,12 \%$ e $85,48 \%$ das microrregiões existentes no Brasil, respectivamente.

\subsubsection{Disponibilidade Relativa dos Serviços Educacionais}

Para tornar mais factível a análise da distribuição espacial do ICE a partir dos resultados do DEA, criaram-se critérios de categorização - cada um sendo representado por uma cor - para cada estrato educacional, tendo como base o 
ano inicial. Primeiramente, calculou-se a quantidade de DMUs com escore igual a $100 \%$, e o restante da amostra foi dividido igualmente em três partes. Dessa forma, obtiveram-se intervalos para cada critério de agrupamento no ano de 2000, e que também foram utilizados para o ano de 2010 para efeitos de comparabilidade e estudo da mobilidade das microrregiões de um ano para outro, conforme apresentado na Tabela 2.

Tabela 2 - Intervalos dos critérios de categorização do ensino fundamental (2000)

\begin{tabular}{l|c}
\hline \multicolumn{1}{c|}{ Critério } & Intervalo \\
\hline Ineficientes & $0,00 \%$ a $88,30 \%$ \\
\hline Baixo & $88,30 \%$ a $93,77 \%$ \\
\hline Intermediário & $93,77 \%$ a $99,99 \%$ \\
\hline Eficiente & $100 \%$ \\
\hline
\end{tabular}

Fonte: Elaboração própria.

Dessa forma, a configuração do ICE para as $558^{17}$ microrregiões segue a distribuição espacial para todos os estratos educacionais, com o seguinte critério: a) preto - microrregiões ineficientes; b) cinza forte - microrregiões com baixa cobertura; c) cinza médio - microrregiões consideradas intermediárias; d) cinza claro - microrregiões eficientes na cobertura educacional; e, por fim, e) branco - as DMUs consideradas outliers.

Especificamente para o estrato educacional do fundamental, a configuração ocorre da seguinte forma: analisou-se 475 microrregiões, das quais 106 formaram a fronteira de melhor disponibilidade relativa dos serviços educacionais. Isso significa dizer que $22,32 \%$ das microrregiões analisadas apresentaram escores de $100 \%$. Com isso, dividiram-se os 77,68\% restantes em três partes iguais, ou seja, em tercis de $25,9 \%$.

A partir dos critérios de categorização do ensino fundamental, expostos na Tabela 2, é possível visualizar a distribuição espacial do ICE para as microrregiões brasileiras do ensino fundamental do ano de 2000, através da ilustração da Figura 1 , e do ano de 2010, na Figura 2.

17 Excluindo os outliers tem-se: 475 para o ensino fundamental e 477 para o ensino médio. 
Figura 1 - Mapa de cobertura educacional do ensino fundamental em 2000, por microrregiões
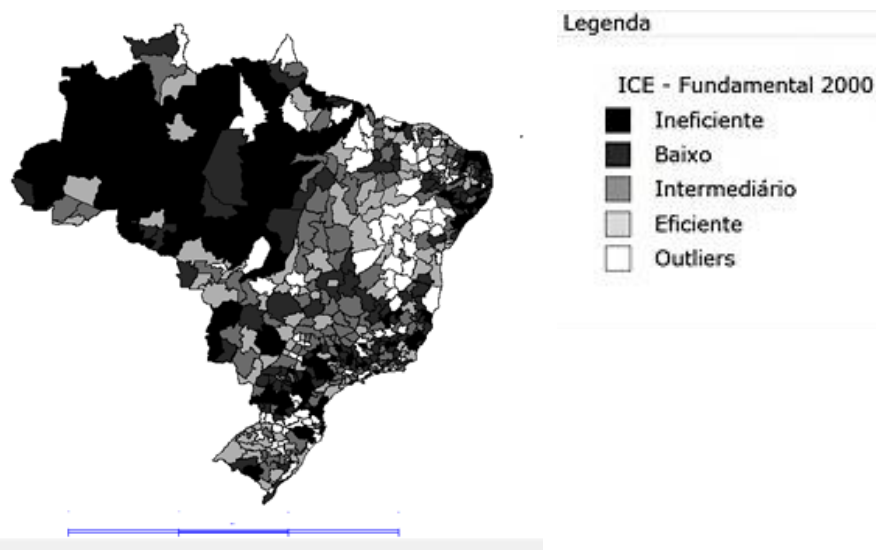

Fonte: Elaboração própria.

Figura 2 - Mapa de cobertura educacional do ensino fundamental em 2010, por microrregiões

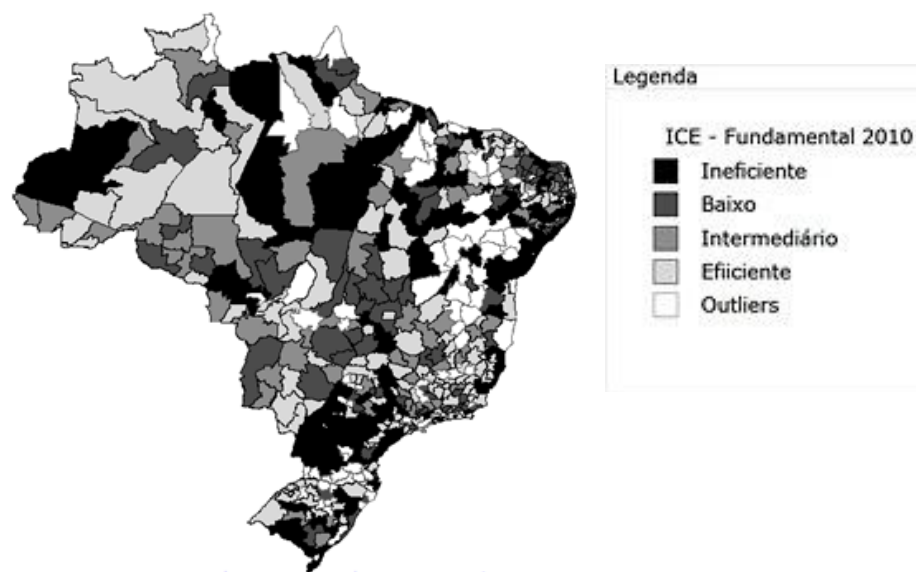

Fonte: Elaboração própria.

É visualmente perceptível que a região Norte é a que mais apresenta microrregiões ineficientes. Isso se confirma em números, pois essa região é a que se apresenta com a maior proporção de microrregiões ineficientes ponderadas pelas quantidades de DMUs analisadas. As proporções gerais obtidas são: Norte $(43,75 \%)$, Sul $(23,4 \%)$, Nordeste $(20,7 \%)$, Sudeste $(15,63 \%)$ e Centro-Oeste (15,78\%). Já as regiões com maiores proporções de eficientes apresentaram os se- 
guintes resultados: Centro-Oeste (32,69\%), Nordeste (18,61\%), Sudeste $(18,13 \%)$, Sul (18,08\%) e Norte (12,5\%).

Considerando os intervalos do critério de categorização (ver Tabela 2), em 2010 o cenário se modifica um pouco, conforme ilustrado na Figura 2. O número de microrregiões eficientes foi de 129, enquanto que, em 2000, era 106, ou seja, houve aumento desse número em torno de $22 \%$. De forma análoga, a quantidade de DMUs ineficientes também aumentou em 2010. Enquanto que em 2000 a quantidade foi de 123 DMUs, em 2010 passa para 178, expressa no aumento de quase $45 \%$. Além disso, ao considerar o intervalo (ver Tabela 2) de 2000, o número de DMUs em 2010 seguiu 178 ineficientes, 82 considerados baixo, 86 intermediários e 129 eficientes, totalizando 475 microrregiões analisadas.

Congênere à análise do ensino fundamental, o ensino médio avaliou 477 microrregiões, das quais, em 2000, 88 formaram a fronteira de melhor disponibilidade relativa dos serviços educacionais desse estrato. A fronteira formada conteve $18,45 \%$ das microrregiões analisadas, bem abaixo da fronteira do ensino fundamental, que foi composta por $22,32 \%$ das 475 analisadas. Para compor os intervalos dos critérios de categorização estabelecidos no estrato anterior, os 81,45\% restantes das DMUs foram divididas, também, em três partes iguais de $27,18 \%$, ou seja, 130 microrregiões em cada tercil.

A Tabela 3 estabelece os intervalos de cada categoria a ser estudada para o ensino médio. Vale enfatizar que os intervalos das categorias baixo e intermediário, mostraram-se melhor distribuídos do que no ensino fundamental. Enquanto que no ensino fundamental o intervalo correspondente à categoria "baixo" satisfez a $88,30<$ ICE < 93,77, no ensino médio esse intervalo se modificou para 69,60< ICE $<85,00$, o que mais condiz com o nome da categoria. Em contrapartida, o limite superior da categoria "ineficientes" foi bem inferior no ensino médio $(69,60 \%)$ do que no fundamental (88,30\%), o que indica que os desempenhos de algumas DMUs no ensino médio foram bem inferiores do que no ensino fundamental, o que pode sinalizar a necessidade de políticas educacionais voltadas para o ensino médio.

Tabela 3 - Intervalos dos critérios de categorização do ensino médio (2000)

\begin{tabular}{l|c}
\hline \multicolumn{1}{c|}{ Critério } & Intervalo \\
\hline Ineficientes & $0,00 \%$ a $69,0 \%$ \\
\hline Baixo & $69,60 \%$ a $85,00 \%$ \\
\hline Intermediário & $85,00 \%$ a $99,99 \%$ \\
\hline Eficiente & $100 \%$ \\
\hline
\end{tabular}

Fonte: Elaboração própria.

De um modo geral, através da Figura 3, é possível perceber um grande contingente de ineficientes ao Norte, mais especificamente nas regiões Norte e Nor- 
deste. De fato, essas regiões foram as que mais apresentaram DMUs ineficientes, traduzidas em 19,38\% e 63,56\% do total de DMUs ineficientes, respectivamente. Quando se analisam as proporções de cada região em relação à quantidade analisada, obtém-se para a região Nordeste o maior percentual, ou seja, 48,62\% das 160 microrregiões analisadas nessa região foram ineficientes. Após a Nordeste, aparece a região Norte, com 41,67\% das 60 microrregiões analisadas, seguida pela região Centro-Oeste, com 16,67\% das 48 analisadas, da região Sul, com 8,75\% das 80 analisadas, e, por fim, a região Sudeste (menor proporção), com 5,83\% das 120 analisadas.

Figura 3 - Mapa de cobertura educacional do ensino médio em 2000, por microrregiões

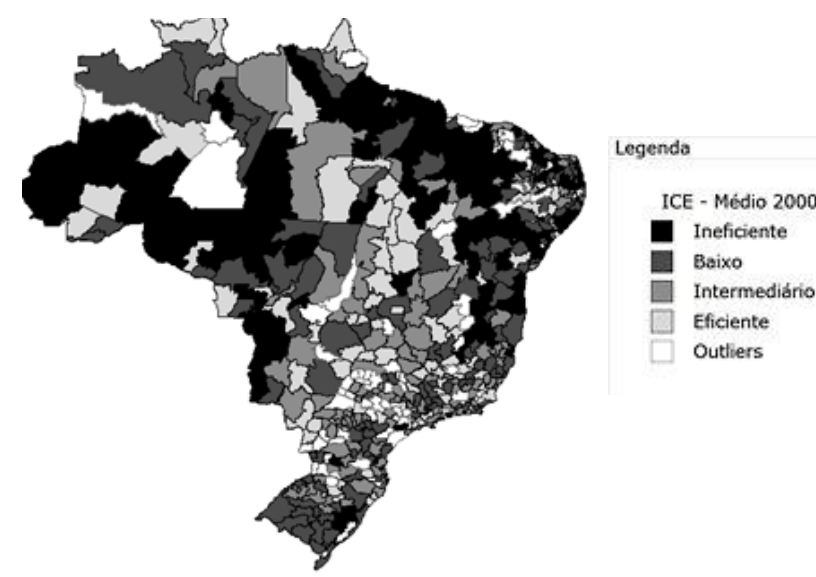

Fonte: Elaboração própria.

No que tange à proporção de eficientes, tem-se a seguinte ordem: Centro-Oeste $(33,33 \%)$, Norte $(26,67 \%)$, Sudeste $(25,0 \%)$, Sul $(12,5 \%)$ e Nordeste (10,65\%). Fica evidente que, para o ano de 2000, do ensino médio, a região Nordeste apresentou os piores índices tanto em magnitude quanto em proporção.

A Figura 4 apresenta o mapa de cobertura educacional para o ano de 2010. Verifica-se uma mudança significativa na distribuição entre os intervalos, principalmente demarcada pelo aumento de $20,45 \%$ de microrregióes consideradas relativamente eficientes e pela redução de 55,39\% das ineficientes na disponibilidade relativa educacional. A distribuição das DMUs entre o intervalo seguiu 477 microrregiões analisadas, das quais 58 foram ineficientes, 94 consideradas com baixa cobertura, 219 intermediárias e 106 eficientes. Isso ilustra uma melhora significativa em relação a 2000, também acompanhada pelo aumento da cobertura média. 
Figura 4 - Mapa de cobertura educacional do ensino médio em 2010, por microrregiões

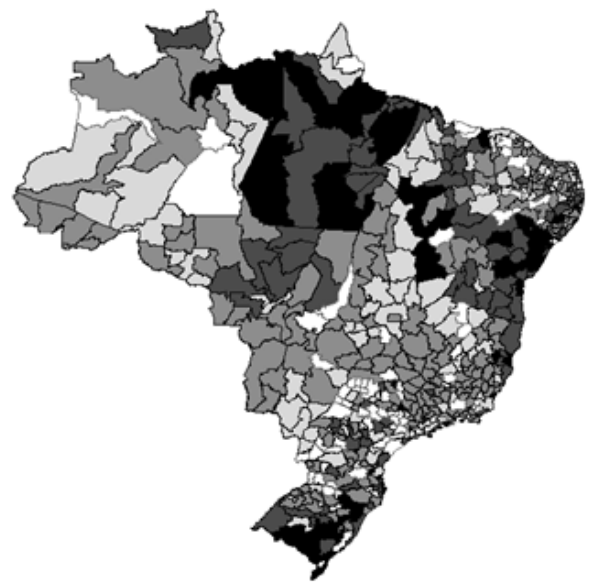

Legenda

ICE - Médio 2010

Ineficiente

Baixo

Intermediário

Eficiente

Outiers

Fonte: Elaboração própria.

Destaca-se, ainda, a boa cobertura apresentada na categoria "intermediária”, com um crescimento de $68,76 \%$ de um ano para o outro. Além disso, considerando-se as categorias "eficientes" e "intermediárias" (boa cobertura), do total de 477 microrregiões, 68,13\% encontram-se em situação favorável em relação às demais, em 2010, em contrapartida a 45,5\% em 2000.

\subsection{Mobilidade Intergeracional Educacional}

\subsubsection{Correlação de Spearman}

O coeficiente da correlação de Spearman ( $\rho$ ) é um coeficiente não paramétrico e adimensional e situa-se no intervalo entre -1 e 1. A ideia é de que, quanto mais próximo de 1, maior será a correlação positiva entre as variáveis. Por sua vez, quando mais próximo de -1, maior será a correlação negativa entre as variáveis. A Tabela 4 apresenta os coeficientes para o Brasil e seus respectivos p-values para os ensinos fundamental e médio.

Tabela 4 - Coeficientes de Spearman entre o ICE e persistência intergeracional educacional de pais analfabetos para os ensinos fundamental e médio em 2000

\begin{tabular}{l|l|l}
\hline \multirow{4}{*}{ Brasil } & \multicolumn{1}{|l|}{ Fundamental } & Médio \\
\cline { 2 - 3 } & \multicolumn{2}{|c}{ Coeficiente de Spearman } \\
\cline { 2 - 3 } & $-0,1649(0,0003)^{*}$ & $-0,3592(0,0000)^{*}$ \\
\hline
\end{tabular}

Fonte: Elaboração própria a partir dos dados da pesquisa.

Nota: * Estatisticamente significativo a um nível de significância de 5\%. 
Verifica-se que tanto para o ensino fundamental, quanto para o ensino médio, o coeficiente foi estatisticamente significativo, o que significa dizer que se rejeita a hipótese nula de que as duas variáveis não estão correlacionadas. Os sinais negativos dos coeficientes indicam que as variáveis variam em sentido contrário, ou seja, as categorias mais elevadas de uma variável estão associadas a categorias mais baixas da outra variável.

Intuitivamente, a priori se poderia inferir que uma melhora na disponibilidade dos serviços públicos educacionais pode diminuir a influência do background familiar na decisão de investir em capital humano, principalmente nos filhos de pais analfabetos. Isso ocorre mais profundamente no ensino médio (correlação maior) do que no fundamental. Contudo, é relevante frisar que é necessária uma investigação mais minuciosa a fim de constatar tal resultado.

Tabela 5 - Coeficientes de Spearman entre o ICE e o índice de Gini educacional para os ensinos fundamental e médio em 2000

\begin{tabular}{lll}
\hline \multirow{2}{*}{ Brasil/regiões } & \multicolumn{1}{c}{ Fundamental } & \multicolumn{1}{c}{ Médio } \\
\cline { 2 - 3 } & \multicolumn{1}{|c}{ Coeficiente de Spearman } \\
\hline Brasil & $-0,2119(0,0000)^{* *}$ & $-0,4306(0,0000) * *$ \\
\hline Norte & $-0,3041(0,0192) * *$ & $-0,2534(0,0408) * *$ \\
\hline Nordeste & $-0,2941(0,0002) * *$ & $-0,2112(0,0058) * *$ \\
\hline Sudeste & $-0,0070(0,9344) *$ & $-0,3298(0,0020) * *$ \\
\hline Sul & $-0,4962(0,0004) * *$ & $-0,2692(0,0158) * *$ \\
\hline Centro-Oeste & $-0,2613(0,0760) * * *$ & $-0,3482(0,0153) * *$ \\
\hline
\end{tabular}

Fonte: Elaboração própria a partir dos dados da pesquisa.

Nota: * Estatisticamente não significativo a um nível de significância de 5\% e 10\%; * * Estatisticamente significativo a um nível de significância de 5\% e 10\%; ** * Estatisticamente significativo a um nível de confiança de $10 \%$.

Além disso, de acordo com Barros et al. (2001), uma melhoria na disponibilidade dos serviços públicos educacionais poderia ser usada para reduzir as desigualdades educacionais no combate ao subinvestimento em capital humano. Para testar a correlação dessa hipótese, estimou-se o coeficiente de correlação de Spearman entre o índice de Gini educacional (representando as desigualdades educacionais) e o ICE. A Tabela 5 apresenta as correlações tanto para o Brasil quanto para as regiões.

Os coeficientes foram todos estatisticamente significativos, exceto a correlação do Sudeste para o ensino fundamental. As maiores correlações estiveram mais fortemente presentes na região Sul, para o ensino fundamental, e na região Centro-Oeste, para o ensino médio. Em termos de país, a correlação negativa é maior para o ensino médio $(-0,43)$ do que para o ensino fundamental $(-0,21)$. No geral, parece haver evidências de que uma melhoria na disponibilidade dos serviços públicos educacionais tende a re- 
duzir as desigualdades educacionais, tanto em termos mais gerais, quanto em disparidades regionais, sendo mais fortemente aplicada para o ensino médio do que para o fundamental.

\subsubsection{Mobilidade Intergeracional Educacional do Brasil e ICE}

Para se investigar se um sistema público educacional mais equitativo tende a melhorar a mobilidade intergeracional educacional, empregou-se o modelo econométrico utilizado em Ferreira e Veloso (2003), com duas importantes distinções. A primeira é que foram cosiderados apenas os filhos com idade de 7 a 14 anos, para o ensino fundamental, e os filhos de 15 a 17 anos, para o médio, ou seja, aqueles em idade escolar. A segunda, e mais importante, é a incorporação de mais uma dummy no modelo, com a finalidade de captar a influência de o pai residir em um local com eficiente cobertura educacional, ou não.

A construção dessa dummy se baseou nos intervalos criados pelos critérios de categorização, expostos na seção anterior. Dessa forma, as microrregiões consideradas ineficientes, ou com baixa cobertura, foram denotadas por 0 e as microrregiões eficientes e intermediárias assumiram os valores de referência 1. 
Tabela 6 - Persistência intergeracional educacional em ambientes com eficiência da oferta educacional (2000)

\begin{tabular}{l|l|l}
\hline \multirow{2}{*}{ Escolaridade do pai } & \multicolumn{1}{c|}{ Fundamental } & \multicolumn{1}{c}{ Médio } \\
\cline { 2 - 3 } & $0.117(0.00)^{*}$ & $0.299(0.00)^{*}$ \\
\hline A (intercepto) & $-5.264(0.00)^{*}$ & $-3.680(0.00)^{*}$ \\
\hline Atributos de localização & $-0.681(0.00)^{*}$ & $-1.259(0.00)^{*}$ \\
\hline Norte & $-0.656(0.00)^{*}$ & $-1.331(0.00)^{*}$ \\
\hline Nordeste & $0.172(0.00)^{*}$ & $0.289(0.00)^{*}$ \\
\hline Sul & $-0.099(0.00)^{*}$ & $-0.310(0.00)^{*}$ \\
\hline Centro-Oeste & $0.170(0.00)^{*}$ & $0.661(0.00)^{*}$ \\
\hline ICE da microrregião & \multicolumn{2}{|l}{} \\
\hline Atributos do filho & $0.039(0.00)^{*}$ & $0.090(0.00)^{*}$ \\
\hline Raça & $-0.267(0.00)^{*}$ & $-0.776(0.00)^{*}$ \\
\hline Sexo & $0.726(0.07)^{* *}$ & $0.554(0.00)^{*}$ \\
\hline Idade & \multicolumn{2}{|l}{} \\
\hline Atributos do pai & $-0.030(0.000)^{*}$ & $-0.087(0.00)^{*}$ \\
\hline Local em que reside (eficiente ou não) 1 & $0.094(0.00)^{*}$ & $0.230(0.00)^{*}$ \\
\hline Sexo & $67 \%$ & $35 \%$ \\
\hline $\mathrm{R}^{2}$ & \multicolumn{2}{|l}{} \\
\hline
\end{tabular}

Fonte: Elaboração própria a partir dos dados da pesquisa.

Nota 1: "Estatisticamente significativo a um nível de significância de 5\% e 10\%; * " Estatisticamente significativo a um nível de significância de $10 \%$.

Nota 2: Essa dummy foi criada pela interação da escolaridade dos pais com a variável eficiente na oferta educacional.

Como mostra a Tabela 6, o grau de persistência no Brasil quando a criança tem idade de estar no ensino fundamental é de 0,11 , o que significa dizer que, se o pai tem um ano de estudo acima da média, seu filho tem um valor esperado de 0,11 ano de estudo acima da média. Contudo, ao avaliar a persistência intergeracional educacional para as pessoas de 15 a 17 anos, verifica-se que o grau aumenta para 0,30 . Esse perfil exprime que a mobilidade intergeracional educacional (1- $\beta$ ) é menor para o ensino médio do que para o fundamental.

Nesse contexto, a geração de oportunidades através de um sistema público educativo que permite atender as necessidades educacionais da população (principalmente das mais pobres) tem um impacto positivo para os dois estratos educacionais, porém mais expressivo no ensino médio $(0,66)$ do que no fundamental $(0,17)$. Em outras palavras, o fato do pai residir em localidades de eficiente cobertura educacional tem o efeito de reduzir em 3\% a persistência intergeracional 
educacional no ensino fundamental e em $8,7 \%$ a persistência dos filhos que estão na faixa etária de cursar o ensino médio.

A importância desta investigação reside - principalmente para o nosso país - no fato de existir uma baixa escolaridade média acompanhada de uma grande desigualdade de renda. Esses fatores limitam as oportunidades dos filhos de pais de baixa renda, que normalmente são aqueles com baixa escolaridade. Então, políticas públicas voltadas a melhorar a oferta da educação pública tende a reduzir os efeitos da persistência intergeracional educacional, o que, por sua vez, melhora a mobilidade intergeracional educacional do país, permitindo melhores oportunidades para aqueles desprovidos de recursos financeiros.

\section{Considerações Finais}

No que tange à caracterização da demanda, boa parte dos estudos, sobretudo os dedicados a analisar o caso brasileiro, tem ressaltado a importância do ambiente familiar na determinação da escolaridade dos filhos através de análises de mobilidade intergeracional educacional. Por sua vez, os fatores ligados à oferta compreendem a economia da educação e têm como objetivo estimar os efeitos do ambiente escolar no resultado educacional dos indivíduos.

Contudo, percebe-se que na literatura da educação os estudos associados à demanda e à oferta por educação tendem a negligenciar a ligação existente entre os fatores determinantes de ambas, limitando-se apenas a analisar uma delas isoladamente. Dentro desse conjunto de informações, o presente trabalho visa complementar essas investigações ao mensurar o impacto dos fatores escolares, retratados neste estudo como a maior disponibilidade dos serviços educacionais sobre a educação dos filhos na medida em que estes residam em locais de eficiente oferta de educação.

A análise foi dividida em duas etapas complementares. A primeira compreendeu a estimação da fronteira de melhor disponibilidade de serviços educacionais para necessidades idênticas às das microrregiões brasileiras com o uso da DEA, o que permitiu representar os déficits relativos da oferta de educação pública no país, como também as microrregiões com eficiente cobertura educacional. O produto da estimação se desdobrou no ICE para os ensinos fundamental e médio nos anos 2000 e 2010 para as 558 microrregiões existentes no Brasil. Além disso, a partir desse índice foi possível investigar a mobilidade da cobertura de 2000 para 2010.

No ensino fundamental, 475 microrregiões foram analisadas, visto que 83 das 558 foram consideradas atípicas. A partir dos critérios de categorização, estabelecidos neste estudo, em 2000 o estrato educacional apresentou 106 microrregiões, com destaque para a região Norte. Já em 2010, o número de eficientes 
aumentou em $22 \%$, passando para 129 microrregiões, com destaque para a região Sudeste. No tocando ao ensino médio, foram analisadas $85,48 \%$ das microrregiões do Brasil, ou seja, apenas 81 apresentaram informações atípicas, o que resultou em uma amostra de 477 DMUs. Em 2000, esse estrato apresentou apenas $88 \mathrm{mi}$ crorregiões eficientes, passando para 106, em 2010, denotando um aumento de $20,5 \%$. Do ponto de vista regional, merece destaque a região Sudeste, que, para os dois anos, apresentou 30 DMUs eficientes, o que representa 25\% das microrregiões analisadas.

A segunda etapa abrangeu as investigações entre o lado da oferta e demanda educacional, partindo do pressuposto de que a decisão de investir em capital humano é influenciada pelo background familiar e pelas condições externas de um sistema educacional mais equitativo. A ideia foi verificar se um ambiente mais favorável para investimento em capital humano, proporcionado por uma melhor oferta pública de educação, pode minimizar os efeitos da persistência intergeracional educacional.

Para testar as correlações, primeiramente foram aplicados testes entre o ICE e a persistência intergeracional educacional dos pais analfabetos. Os resultados apontaram que existe uma correlação negativa entre as variáveis, o que a priori nos levar a concluir que uma melhora na disponibilidade dos serviços públicos educacionais pode diminuir a influência do background familiar na decisão de investir em capital humano, principalmente dos filhos de pais analfabetos. Isso ocorre mais profundamente no ensino médio (correlação maior) do que no fundamental. Ao se realizar o teste entre o ICE e o índice de Gini educacional (representando as desigualdades educacionais), pareceu haver evidências de que uma melhoria na disponibilidade dos serviços públicos educacionais tende a reduzir as desigualdades educacionais, tanto em termos mais gerais, quanto em relação a disparidades regionais, sendo mais fortemente aplicada para o ensino médio do que para o fundamental. Contudo, é relevante frisar que é necessária uma investigação mais minuciosa a fim de constatar tal resultado.

Por fim, para investigar se um sistema público educacional mais equitativo tende a melhorar a mobilidade intergeracional educacional, empregou-se o modelo econométrico utilizado por Ferreira e Veloso (2003). As principais conclusões são de que a geração de oportunidades através de um sistema público educativo, permitindo atender as necessidades educacionais da população (principalmente as mais pobres), tem um impacto positivo para os dois estratos educacionais, porém mais expressivo no ensino médio $(0,66)$ do que no fundamental $(0,17)$. Em outras palavras, o fato do pai residir em localidades de eficiente cobertura educacional tem o efeito de reduzir em $3 \%$ a persistência intergeracional educacional no ensino fundamental e em $8,7 \%$ a persistência dos filhos que estão na faixa etária de cursar o ensino médio. 


\section{Referências}

AAKVIK, A.; VAAGE, K.; SALVANES, K. G. Educational attainment and family background. German Economic Review, v. 6, n. 3, p. 377-394, 2005.

ALBERNAZ, A.; FERREIRA, F. H. G.; FRANCO, C. Qualidade e equidade na educação fundamental brasileira. Rio de Janeiro: PUC, maio, 2002. (Texto para discussão n. 455).

AMMERMÜLLER, A. Educational opportunies and the role of institutions. Centre for European Economic Research (ZEW), June 2005. (Discussion papers, 05-44).

BAGOLIN, I. P.; PÔRTO JÚNIOR, S. S. A desigualdade da distribuição da educação e crescimento no Brasil: índice de Gini e anos de escolaridade. Revista Estudos do Cepe, Santa Cruz do Sul, RS, n. 18, 2003.

BALSMEIER, B.; PETERS, H. Family background or the characteristics of children: what determines high school success in Germany? Berlin: DIW Berlin, The German Socio-Economic Panel (SOEP), Oct. 2008. (Discussion papers n. 138).

BANKER, R. D.; CHARNES, A.; COOPER, W. W. Some models for estimating technical and scale inefficiencies in data envelopment analysis. Management Science, v. 13, n. 9, p. 10781092, Sept. 1984.

BARRO, R. J.; LEE, J. International data on education attainment: updates and implications. Cambridge: NBER, Sept. 2000. (Working paper, n. 7911).

BARROS, R. P. et al. Determinantes do Desempenho Educacional no Brasil. Rio de Janeiro: IPEA, out. 2001. (Texto para discussão, n. 834).

BECKER, G. S.; TOMES, N. An equilibrium theory of the distribution of income and intergenerational mobility. Journal of Political Economy. Chicago, v. 87, n. 6, p. 1153-1189, Dec. 1979.

BEHRMAN, J. R .; G., A.; SZÉKELY, M. Mobilidade intergeracional na América Latina. Economia , v. 2, n. 1, p. 1-31, 2001.

BIRCHENALL, J. A. Income distribution, human capital and economic growth in Colombia. Journal of Development Economics, Amsterdam, v. 66, n. 1, p. 271-287, Oct. 2001.

BJÖRKLUND, A.; JÄNTTI, M. Intergenerational income mobility in Sweden compared to the United States. American Economic Review, v. 87, n. 5, p. 1009-1018, 1997.

BRASIL. Constituição. Constituição da República Federativa do Brasil. Brasília, DF: Senado Federal, 1988.

. Lei $n^{\circ}$ 11.274, de 6 de fevereiro de 2006. Altera a redação dos arts. 29, 30, 32 e 87 da Lei no 9.394, de 20 de dezembro de 1996, que estabelece as diretrizes e bases da educação nacional, dispondo sobre a duração de 9 (nove) anos para o ensino fundamental, com matrícula obrigatória a partir dos 6 (seis) anos de idade. Disponível em: <http:/www. planalto.gov.br/ccivil_03/_Ato2004-2006/2006/Lei/11274.htm> . Acesso em: 12/fev/2013. 
BRUNELLO, G.; CHECCHI, D. Does school traking affect equality of opportuny: new international evidence. Germany; Institute for the Study of Labor (IZA), Set. 2006. (Discussion papers series, n. 2348).

CERONI, C. Poverty traps and human capital accumulation. Economica, London, v. 68, n. 270, p. 203-19, May 2001.

CHARNES, A.; COOPER, W.W.; RHODES, E. Measuring the efficiency of decision making units. European Journal of Operational Research, v. 2, n. 6, p. 429-444, 1978.

CHECCHI, D.; ICHINO, A.; RUSTICHINI, A. More equal but less mobile? Education financing and intergenerational mobility in Italy and in the US. Journal of Public Economic, New York, v. 74, n. 3, p. 351-393, Mar. 1999.

CHEVALIER, A.; DENNY, K.; McMAHON, D. A multi-country study of inter-generational educational mobility, May 2003. (Working papers n. 200314)

ERMISCH, J.; FRANCESCONI, J. Family matters: impacts of family background on educational attainments. Economica, London, v. 68, n. 270, p. 137-56, May 2001.

. Intergenerational mobility in Britain: new evidence from the British household panel study. In: CORAK, M. (Ed.). Generational income mobility in North America and Europe. New York, Cambridge University Press, 2004. p. 147-189.

FARRELL, M. J. The measurement of productive efficiency. Journal of the Statistical Society, V. 120, n. 3, p. 253-281, 1957.

FERREIRA, C. M. C.; GOMES, A. P. Introdução à análise envoltória de dados: teoria, modelos e aplicações. Viçosa, MG: Editora da UFV, 2009.

FERREIRA, S.; VELOSO, F.. Mobilidade intergeracional de educação no Brasil. Pesquisa e Planejamento Econômico, Rio de Janeiro, v. 33, n. 3, p. 481-513, 2003.

. A reforma da educação. In: CASTELAR, A.; GIAMBIAGI, F. Rompendo o marasmo: a retomada do desenvolvimento no Brasil. Rio de Janeiro: Elsevier, 2006. p. 251-279.

ECONOMIA E DESENVOLVIMENTO. Recife, v. 8, n. 1, 2009.

FIGUEIRÊDO, E. A.; NETTO JÚNIOR, J. L.; PORTO JÚNIOR, S. S. Distribuição, mobilidade e polarização de renda no Brasil: 1987 a 2003. Revista Brasileira de Economia. Rio de Janeiro, v. 61, n. 1, p. 7-32, jan./mar. 2007.

GALOR, O.; TSIDDON, D. Thecnological progress, mobility and economic growth. American Economic Review, v. 87, n. 3, p. 363-82, June 1997.

GASPARINI, C. E.; COSTA, R. F. R.; SAMPAIO, L. M. B. FPM e equidade de serviços públicos: um estudo para os municípios nordestinos. In: ENCONTRO REGIONAL DE ECONOMIA, 14., 2009, Fortaleza. Anais... Fortaleza: Anpec, 2009.

GREENE, W. H. Econometric analysis. New York: Prentice Hall, 2002. 
HANUSHEK, E.; WÖBMANN, L. Does educational tracking affect performance and inequality? Differences-in-differences evidence across countries. The Economic Journal, v. 116, n. 3, p. C63-C76, Mar. 2006.

JONES, C. I. Introdução à Teoria do Crescimento Econômico. 16. ed. Rio de Janeiro: Elsevier, 2000 .

LEE, J. W.; BARRO, R. J. Schooling quality in a cross-section of countries. Economica, v. 68, n. 271, p. 465-488, Nov. 1997.

LUCAS, R. E. J. On the mechanics of economics development. Journal of Monetary Economic, Chicago, v. 22, p. 3-42, Feb. 1988.

MANKIW, N.; ROMER, D.; WEIL, D. A contribution to the empirics of economic growth. Quartely Journal of Economics, v. 107, n. 2, p. 407-37, May. 1992.

MENEZES FILHO, N. A. Qualidade da Educação. In: SICSÚ, J.; CASTELAR, A. Sociedade e economia: estratégias de crescimento e desenvolvimento. Brasília: Ipea, 2009. p. 201-209.

MINCER, J. Investiment in human capital and personal income distribution. The Journal of Political Economy, New York, v. 66, n. 4, p. 281-302, Aug. 1958.

. Schooling and earnings. In: MINCER, J. Schooling, experience and earnings. Columbia: University Press, 1974, p. 41-63.

PUIG-JUNOY, J. Radial measures of public services deficit for regional allocation of public funds. Barcelona: Universitat Pompeu Fabra, Dec. 1999. (Economics working paper, n. 439).

RIANI, J. L. R.; RIOS-NETO, E. L. G. Background familiar versus perfil escolar do município: qual possui maior impacto no resultado dos alunos brasileiros? Revista Brasileira de Estudos de Pop., São Paulo, v. 25, n. 2, p. 251-269, jul./dez. 2008.

RIOS-NETO, E. L. G.; CÉSAR, C. C.; RIANI, J. L. R. Estratificação educacional e progressão escolar por série no Brasil. Pesquisa e Planejamento Econômico, Rio de Janeiro, v. 32, n. 3, p. 395-415, dez. 2002.

ROMER, P. M. Increasing returns and long-run growth. Journal of Political Economy, v. 94, n. 5, p. 1002-1037, Oct. 1986.

Human capital and growth: theory and evidence. Journal Carnegie Rochester conference series on Public Policy, v. 32, n. 1, p. 251-286, Jan. 1990.

NETTO JÚNIOR, J. L. S.; RAMALHO, H. B.; ARAGON, E. K. B. Transmissão intergeracional de educação e mobilidade de renda no Brasil. In: ENCONTRO NACIONAL DE ECONOMIA, 38., 2010, Salvador. Anais... Salvador: Anpec, 2010.

NETTO JÚNIOR, J. L. S.; FIGUEIREDO, E. A. Distribuição de capital humano e desigualdade de renda: mobilidade intergeracional educacional e mobilidade de renda no Brasil. Revista Economia e Desenvolvimento, v. 8, n. 1, p. 186-231, 2009.

SOLOW, R. M. A contribution to the theory of economic growth. Quarterly Journal of Economics, v. 70, n. 1, p. 65-94, Feb. 1956. 
. Technical change and the aggregate production function. Review of Economics and Statistics, v. 39, n. 3, p. 312-320, Aug. 1957.

SOUSA, M. C. S.; STOŠIĆ, B. D. Technical efficiency of the Brazilian municipalities: correcting nonparametric frontier measurements for outliers. Journal of Productivity Analysis, v. 24, n. 2, p. 157-181, Oct. 2005.

STOŠIĆ, B. D.; SOUSA, M. C. S. Jackstrapping DEA scores for robust efficiency measurement. In: ENCONTRO BRASILEIRO DE ECONOMETRIA, 25., 2003, Porto Seguro. Anais... Porto Seguro: Sociedade Brasileira de Econometria, 2003. p. 1525-1540.

THOMAS, V.; WANG, Y.; FAN, X. Measuring education inequality: Gini coeficientes of education. Washington, D.C.: World Bank Institute, 2000.

Recebido em: 23/01/2013. Aceito em: 04/03/2015. 